\title{
Development of a three dimensional circulation model based on fractional step method
}

\author{
Mazen Abualtayef ${ }^{1}$, Masamitsu Kuroiwa ${ }^{1}$, Ahmed Khaled Seif ${ }^{2}$, Yuhei Matsubara ${ }^{1}$, Ahmed M. Aly ${ }^{2}$, \\ Ahmed A. Sayed ${ }^{2}$ and Alioune Nar Sambe ${ }^{3}$ \\ ${ }^{I}$ Department of Civil Engineering, Tottori University, Koyama, Tottori, Japan \\ ${ }^{2}$ National Water Research Center, Cairo, Egypt \\ ${ }^{3}$ Laboratoire de Sondages Electromagn'etiques de l Environnement Terrestre, France
}

\begin{abstract}
A numerical model was developed for simulating a three-dimensional multilayer hydrodynamic and thermodynamic model in domains with irregular bottom topography. The model was designed for examining the interactions between flow and topography. The model was based on the three-dimensional Navier-Stokes equations and was solved using the fractional step method, which combines the finite difference method in the horizontal plane and the finite element method in the vertical plane. The numerical techniques were described and the model test and application were presented. For the model application to the northern part of Ariake Sea, the hydrodynamic and thermodynamic results were predicted. The numerically predicted amplitudes and phase angles were well consistent with the field observations.
\end{abstract}

KEY WORDS: Hydrodynamic; Thermodynamic; Wetting and drying; Tidal current; Density current; Fractional step method; Ariake Sea.

\section{INTRODUCTION}

Numerical models of ocean circulation are among the most demanding tasks performed by computers today. During the past few decades, several three-dimensional (3D) circulation models have been developed, e.g., those of Heaps (1972), Jin and Kranenburg (1993), Zhang and Gin (2000), and $\mathrm{Yu}$ and Kyozuka (2004), and some of the ocean models are using two-dimensional (2D) part of the dynamics (i.e. sea surface elevation, depth mean currents) and 3D part containing the vertical distribution of currents, salinity and temperature (for example: Oey, 2005). However, our model is solving the $3 \mathrm{D}$ momentum equations for the currents and tracers.

This model is a 3D hydrodynamic ocean model, which computes the time evolution of sea surface elevation, currents, wetting and drying (WAD), salinity, and temperature. In addition, the thermodynamics are described by the 3D advection-diffusion equations for salinity and temperature. The advantage of using our regular fixed grid model, which uses the Cartesian coordinate system, is to resolve the complicated topographic features, with high vertical resolution in shallow areas, by dividing the water depth into equal layers. It is also possible to finely to divide the near

Corresponding author: Mazen Abualtayef

e-mail:mazen_tayef@yahoo.com sea-bottom layer. Therefore, the vertical flow distribution can be calculated even in extremely shallow sea areas. The model was calibrated and validated using several standard tests against analytical solutions, and the model results were well consistent with the analytical solutions (Abualtayef et al., 2007, 2008).

This article presents the theory, the model test to simulate the ocean circulation, and the model application to the Ariake Sea. This model is capable of being developed as an environmental coastal area model, and this will be the final goal of the ongoing research. The objective of this study was to formulate and develop a 3D numerical model to clarify the hydrodynamic and thermodynamic of the Ariake Sea.

\section{MATHEMATICAL FORMULATION}

The governing equations in the Cartesian coordinate system, with $x$-axis and $y$-axis set on the still water level and the $z$-axis taken upward direction from the still water level, are:

$$
\begin{aligned}
& \frac{\partial \mathbf{u}}{\partial t}+\mathbf{u} \cdot \nabla \mathbf{u}=-\frac{1}{\rho} \nabla p+\mathbf{g}+\nabla \cdot(\varepsilon \nabla \mathbf{u})+\mathbf{u} f \\
& \nabla \cdot \mathbf{u}=0 \\
& \frac{\partial T}{\partial t}+\mathbf{u} \cdot \nabla T=\nabla \cdot\left(\varepsilon_{T} \nabla T\right)
\end{aligned}
$$




$$
\begin{aligned}
& \frac{\partial S}{\partial t}+\mathbf{u} \cdot \nabla S=\nabla \cdot\left(\varepsilon_{S} \nabla S\right) \\
& \frac{\partial \eta}{\partial t}=-\frac{\partial}{\partial x} \int_{-h}^{\eta} u d z-\frac{\partial}{\partial y} \int_{-h}^{\eta} v d z \\
& \rho=\rho(T, S) \\
& \rho=\frac{\sigma_{t}}{1000}+1 \\
& \sigma_{t}=\sum_{t}+\left(\sigma_{0}+0.1324\right)\left\{1-A_{t}+B_{t}\left(\sigma_{0}+0.1324\right)\right\} \\
& \sigma_{0}=-0.069+1.4708 S-0.00157 S^{2}+0.0000398 S^{3} \\
& \sum_{t}=-\frac{(T-3.98)^{2}}{503.570} \cdot \frac{T+28.03}{T+67.26} \\
& A_{t}=T\left(4.7869-0.098185 T+0.0010843 T^{2}\right) \times 10^{-3} \\
& B_{t}=T\left(18.03-0.8164 T+0.01667 T^{2}\right) \times 10^{-6}
\end{aligned}
$$

where the velocity vector $\mathbf{u}$ components are $u, v$, and $w$ along axes $x, y$, and $z$, respectively; $t$ is the time; $f$ is the Coriolis parameter calculated by $2 \Omega \sin \varphi(\Omega$ is the rotational angular velocity of the Earth); $\varphi$ is the latitude; $\eta$ is the water surface displacement, $h$ is the water depth below the reference plane; $\rho$ is the water density; $\mathbf{g}$ is the acceleration of gravity; $\varepsilon$ is the eddy viscosity coefficient defined by Smagorinsky model; $\varepsilon_{T}$ is the diffusion coefficient for heat; and $\varepsilon_{S}$ is the diffusion coefficient for salinity.

The boundary conditions are:

1. At the sea surface: the surface stress and the surface salt flux are zero.

2. At the ocean bottom: the bottom shear stresses are given by

$\varepsilon_{z} \frac{\partial u}{\partial z}=\frac{\tau_{b x}}{\rho}, \varepsilon_{z} \frac{\partial v}{\partial z}=\frac{\tau_{b y}}{\rho} \quad(z=-h)$

where $\tau_{b x}$ and $\tau_{b y}$ are

$\left.\begin{array}{rl}\tau_{b x} & =\rho g u \sqrt{u^{2}+v^{2}} / C^{2} \\ \tau_{b y} & =\rho g v \sqrt{u^{2}+v^{2}} / C^{2}\end{array}\right\}$

where $C$ is the Chezy coefficient, and the vertical velocity, $w$, in the bottom layer is given by

$w=-u \frac{\partial h}{\partial x}-v \frac{\partial h}{\partial y}$

3. At the coast: a moving boundary condition was considered. We give here a WAD scheme to determine the coastline position at each time step and extrapolate the $3 \mathrm{D}$ predictive variables onto the tidal flat only when the water depth exceeds a pre-assigned depth, $d_{d r y}$. The normal flow and the normal fluxes of momentum and salt vanish when the water depth drops below $d_{d r y}$.
4. At the open ocean end, the change of water level due to the lunar semi-diurnal tide, $M_{2}$, was set at the offshore region. The change of water level assumes a sinusoidal function, which has its phase in the alongshore direction, and thus both open sea sides in the alongshore direction were set up as periodic boundaries.

The governing equations were solved using the fractional step method, originally suggested by Koutitas and O'Connor (1980). This method combines the finite difference method in the horizontal plane, and the Galerkin finite element method (FEM) in the vertical direction. This hybrid method was used to solve the equation of motion by dividing it into two differential sections and integrating separately for the two stages. Because the FEM was used in the vertical direction, the water depth could be divided into equal layer thicknesses, and near the sea-bottom layer, a fine division was possible. In this computation, the position of variables was defined using a space-staggered grid system.

The present model consists of four modules: the tidal current module, salinity circulation module, water temperature circulation module, and WAD module. Governing equations for the current velocities, with the Bussinesq turburence approximation, were derived from the continuity equation and the 3D Navier Stokes equations. The current compuations include the effect of the mixing processes due to the changes of salinity and temperature. The 3D distributions of the salinity and temperature were determined using the 3D advection-diffusion equations. The WAD scheme is originaly suggested by Kato et al. (1979), and the geographycal features are proposed by the authors (Abualtayef et al., 2008).

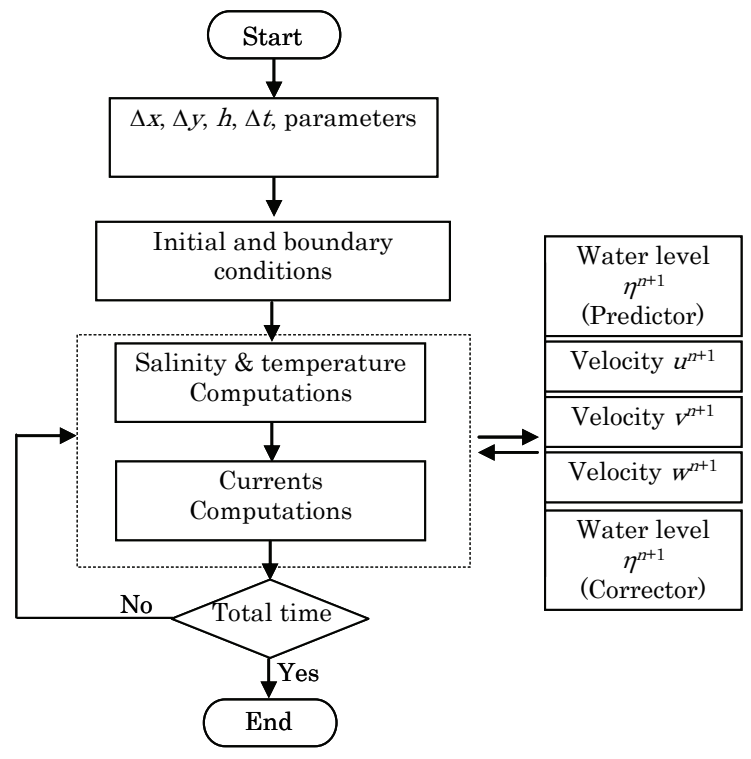

Fig. 1 Flow chart of numerical computations.

The computational domain in the $x-y$ plane was divided into a rectangular grid. The vertical component of the current velocity $(w)$ and mean water level $(\eta)$ were computed at the center of each grid cell, whereas the horizontal velocity 
components $u$ and $v$ were corrected midway along the cell faces. The mean water surface level for the next time step $\left(\eta^{n+1}\right)$ was evaluated by using the previous time step $\left(\eta^{n-1}\right)$. The flowchart of the numeric computations is shown in Fig. 1.

\section{MODEL TESTS}

In the second phase for the development of the present model, the model was verified using several numerical tests and the results were identical to the analytical solutions (Abualtayef et al., 2007, 2008). In this article, a density current test and an artificial tidal flat test were provided without aiming for formal verification, but immediately showing the model's capabilities.

\section{Density current test}

Before performing the tide calculation with the consideration of density changes, the density current was computed in an enclosed basin in order to confirm the characteristic of density current, as shown in Fig. 2.

The horizontal computational domain was covered an area of $3 \times 3 \mathrm{~km}$, with a grid interval of $100 \mathrm{~m}$; the water depth was assumed uniform with $10 \mathrm{~m}$ deep; the water depth was divided into five equal layers; the total period was $12 h$; the time step was $1.0 s$; the salinity and water temperature were given at center part $(x, y, z)=(1500,1500,-5 m)$ in the computation area as a source point, and the reproduction of diffusion as well as the density current were confirmed. The horizontal and vertical eddy viscosity coefficients were defined by trial and error method to express the state of density current and they were 50.0 and 0.001 , respectively. The horizontal diffusion coefficient was defined by Richardson multiplication rule $4 / 3$ as $K_{c}=0.01 Y^{4 / 3}$, which shows the width of the extension of diffusion $Y(\mathrm{~cm})$, and the calculation area of $3.0 \times 10^{5} \mathrm{~cm}$ was substituted in this calculation. The smaller value of the horizontal diffusion coefficient from Richardson's 4/3 multiplication rule and $20.0 \mathrm{~m}^{2} / \mathrm{s}$ was used. According to Ueno (1998), the value of vertical eddy viscosity in the tidal area is within a range from 0.1 to $1.0 \mathrm{~m}^{2} / \mathrm{s}$.

Table 1 Source point input condition for density current test.

\begin{tabular}{|c|c|c|c|}
\hline & CASE 1 & CASE 2 & CASE 3 \\
\hline Water temperature, ${ }^{\circ} \mathrm{C}$ & 22.0 & 18.0 & 18.0 \\
\hline Salinity, \%o & 16.0 & 0.0 & 16.0 \\
\hline
\end{tabular}

The initial water temperature was $22.0^{\circ} \mathrm{C}$ and the initial salinity was $0.0 \%$. In addition, to confirm the density current, the tidal flow was not considered. To compare the results, three cases were simulated to give a density change at a source point, as shown in Table 1.

The computed results after $12 h$ from the calculation start for CASE 1 is shown in Fig. 3. In CASE 1, the appearance of symmetrical diffusion around source point was confirmed.
The density gradually increases (salt wedge) with a counter clockwise density current circulation on the right side and a clockwise on the left side, as shown in Fig. 3(a). It can be confirmed that the diffusion was advanced by centering on the source point from Fig. 3(b) to (c) and look like a concentric circle. It is understood that the distribution is closer to surfaces than the bottom layer, and the diffusion at the bottom layer is faster than at the surface. It was found that the flow by the density difference was reproduced.

In CASE 2, the outbreak of the salt wedge such as CASE 1 was not seen and the water temperature has almost similar distribution in the vertical direction. Moreover, the flow velocity was not confirmed. It was found that the density changes due to the water temperature changes were smaller than that due to the salinity changes. However, the diffusion of horizontal direction was a state of the concentric circles.

In CASE 3, the water temperature distribution in the vertical direction was same as in CASE 2. The current results in CASE 3 are $0.3 \%$ slightly higher than those in CASE 1.

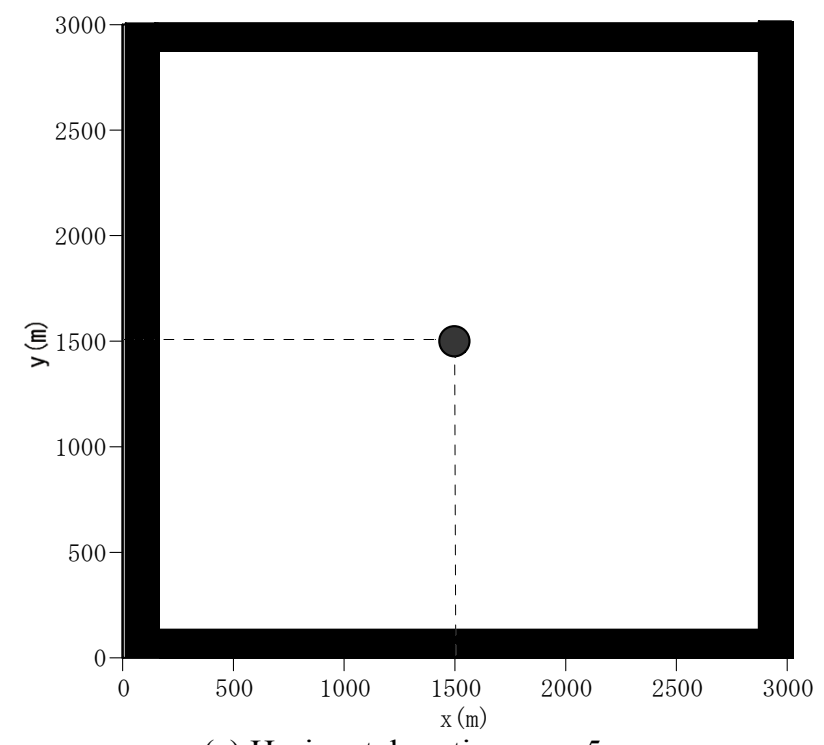

(a) Horizontal section, $z=-5 m$.

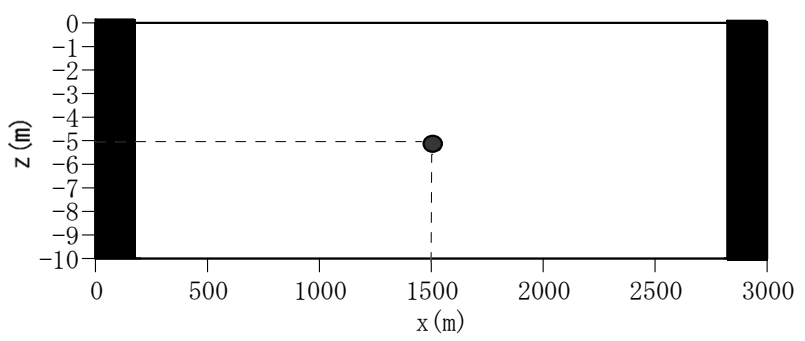

(b) Vertical section at $y=1500 \mathrm{~m}$.

Fig. 2 Computational domain for density current test.

The water temperature and salinity diffusions were influenced the density current, and it was confirmed that the density change by the salinity contributed greatly to the density current. Therefore, the results of water density due to the change of water temperature and salinity are shown in Table 2. It was concluded that the water density was more 
significantly influenced by the salinity changes than the water temperature changes.

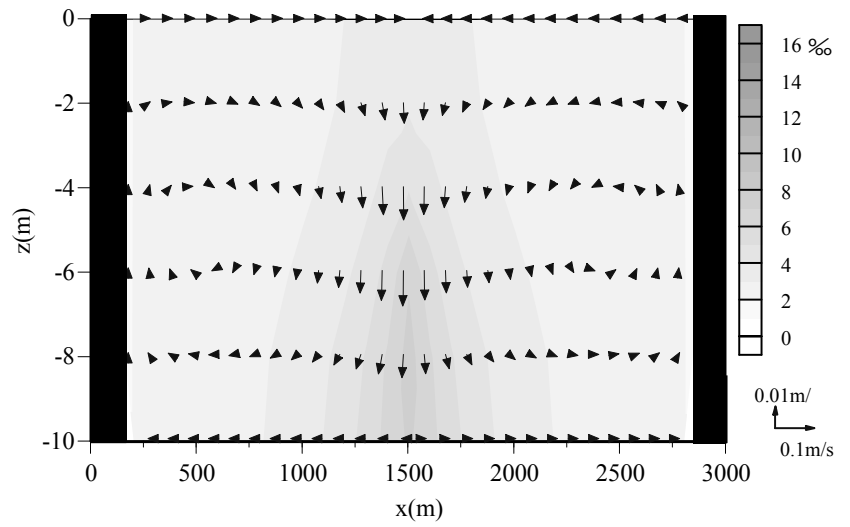

(a) Salinity and density current in the vertical section.

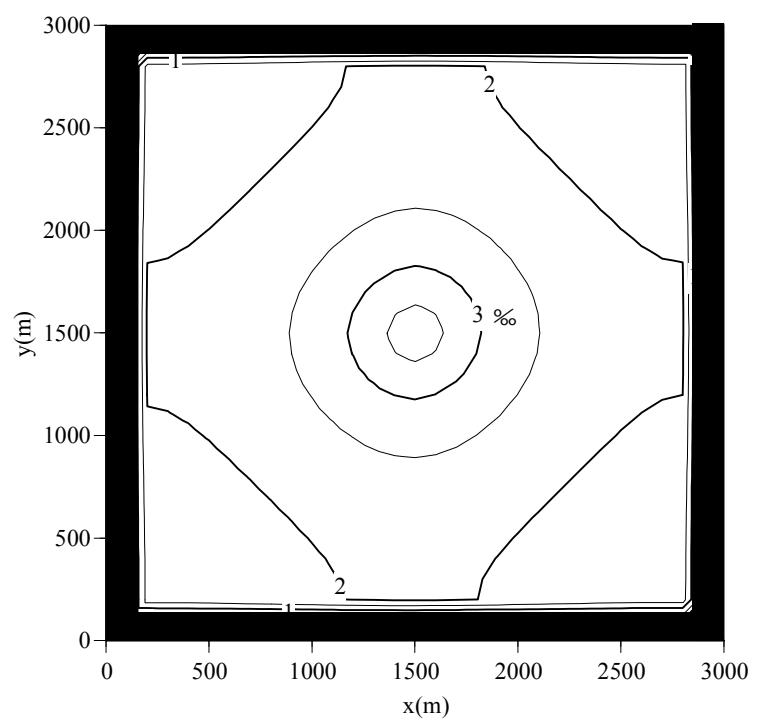

(b) Salinity distribution at the surface layer.

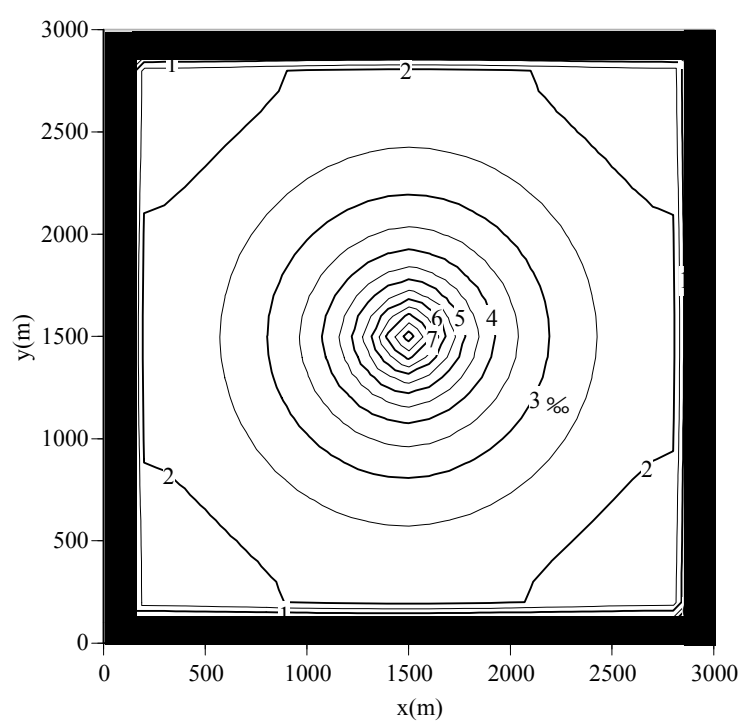

(c) Salinity distribution at the bottom layer.

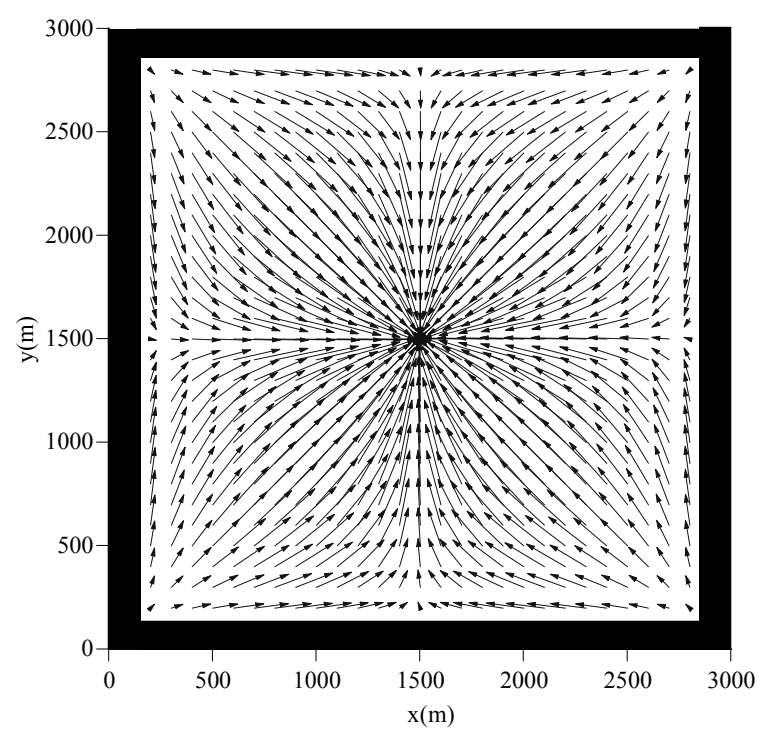

(d) Density current at the surface layer.

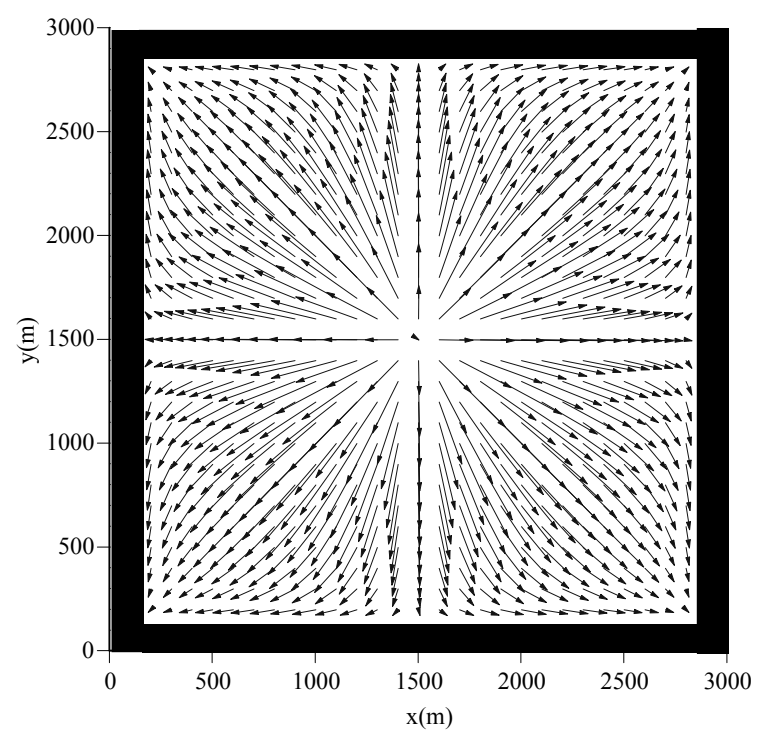

(e) Density current at the bottom layer.

Fig. 3 Computed results of CASE 1.

Table 2 Influence of water temperature and salinity rates upon the density of water (unit in $\mathrm{kg} / \mathrm{m}^{3}$ ).

\begin{tabular}{|c|c|c|c|}
\hline \multirow{2}{*}{ Salinity } & \multicolumn{3}{|c|}{ Water temperature } \\
\cline { 2 - 4 } & $0.0^{\circ} \mathrm{C}$ & $15.0^{\circ} \mathrm{C}$ & $30.0^{\circ} \mathrm{C}$ \\
\hline $0.0 \% o$ & 1000.02 & 999.91 & 999.23 \\
\hline $8.0 \% o$ & 1012.16 & 1011.42 & 1010.38 \\
\hline $16.0 \% o$ & 1024.22 & 1022.89 & 1021.52 \\
\hline
\end{tabular}

\section{Artificial tidal flat test with flat bed}

To apply the thermodynamic model to real case, first it was necessary to verify the model in an easy geographical features model test to investigate the characteristic of the 
numerical model. Therefore, currents were computed for a basin with a flat bottom as shown in Fig. 4. The effect of including and excluding the thermodynamic was examined and compared.

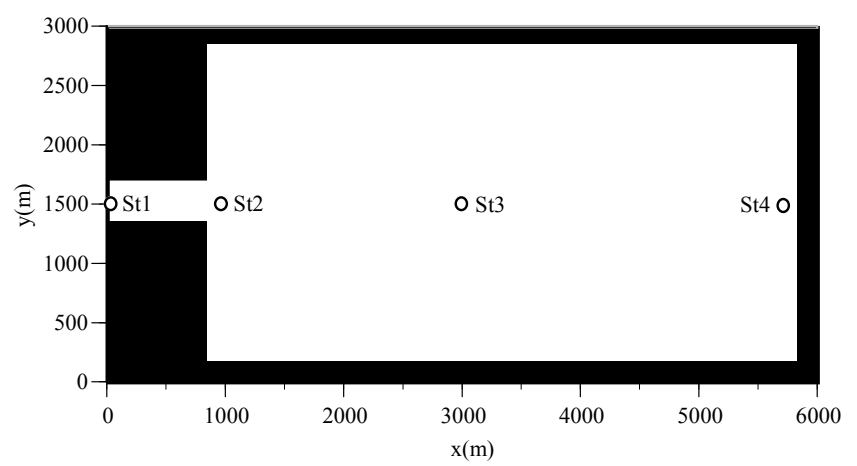

Fig. 4 Computational domain of artificial tidal flat test.

The horizontal computational domain considered in this test covered an area of $6 \times 3 \mathrm{~km}$, with a grid interval of $100 \mathrm{~m}$; the water depth was assumed uniform with $10 \mathrm{~m}$ deep; the water depth was divided into five equal layers; the total period was $48 h$; and the time step was $1.0 \mathrm{~s}$. The horizontal and vertical eddy viscosity coefficients were defined by trial and error method to express the state of density current and they were 50.0 and 0.01 , respectively. The horizontal and vertical diffusion coefficients were 50.0 and 0.005 . The initial water temperature was $22.0^{\circ} \mathrm{C}$ and the initial salinity was $0.0 \%$ (fresh water). In addition, to confirm the density current, the tidal flow was not considered in CASE 1. To compare the results, three cases were simulated as shown in Table 3. The boundary condition of the salinity rate of $16 \%$ was given at the open boundary at the left-side of Fig. 4. In this computation, only the tide was given during the $M_{2}$ component, and the water level change was given as a sinusoidal function at open boundary.

Table 3 The conditions of computational cases.

\begin{tabular}{|l|c|c|c|}
\hline & CASE 1 & CASE 2 & CASE 3 \\
\hline Amplitude $(m)$ & 0.0 & 1.0 & 1.0 \\
\hline Salinity change & Yes & No & Yes \\
\hline
\end{tabular}

The computed results of the fourth period after reaching the steady state were considered and analyzed. The results of the water level of CASE 1 to CASE 3 are shown in Fig. 5. Immediately after the model run, a vibration in water level in all cases could be seen, but as the calculation step was advanced, the vibration was vanished and the steady state was reached. In CASE 2, which excluded the salinity change, there was a slight difference in water level between the entrance (St1) and the basin head (St4). This is due to the non-linear effect in the terms of water level equation. However, in CASE 3 in which the density change was considered, the water level was gradually increased toward the basin head, which was due to the seawater flowed in large quantities into the basin as a result of the density current.

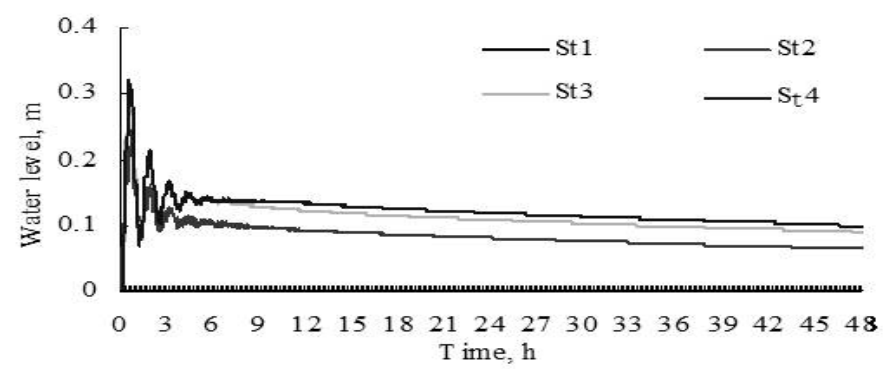

(a) CASE 1

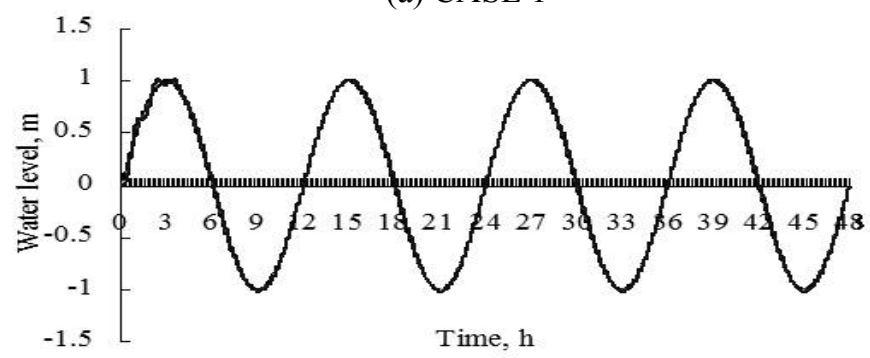

(b) CASE 2

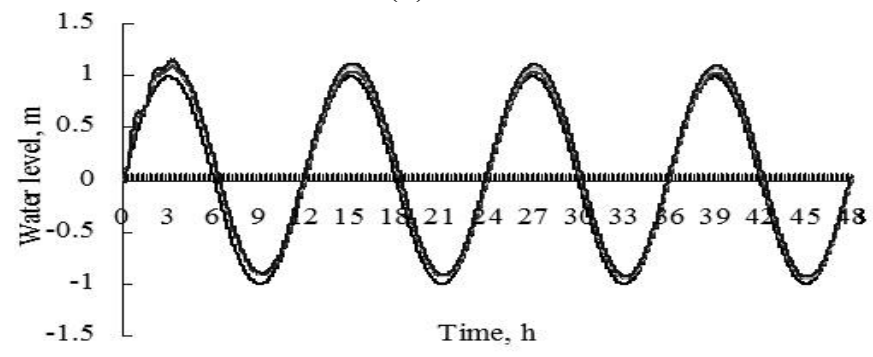

(c) CASE 3

Fig. 5 The water level changes.

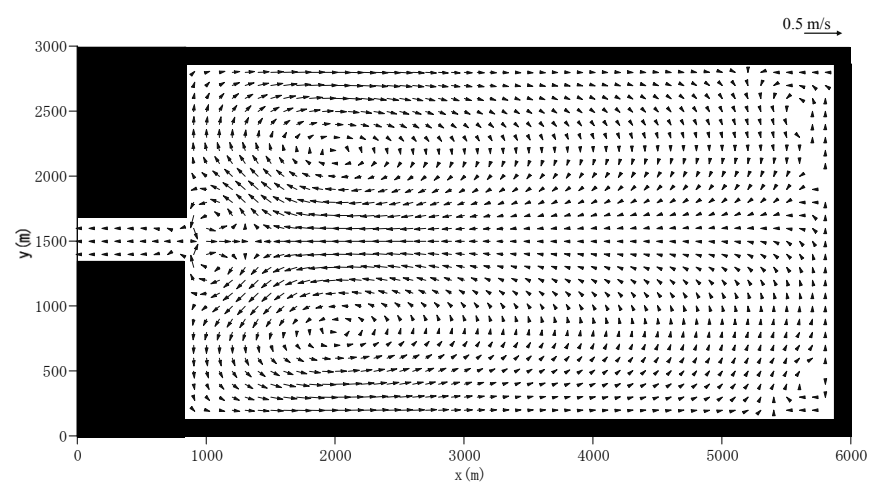

(a) Depth average currents vector.

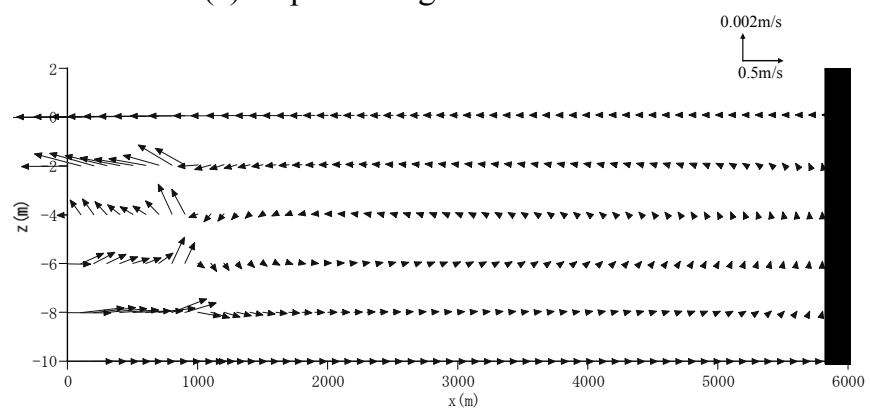

(b) Vertical currents vectors $(y=1500)$.

Fig. 6 Computed result of CASE 1. 


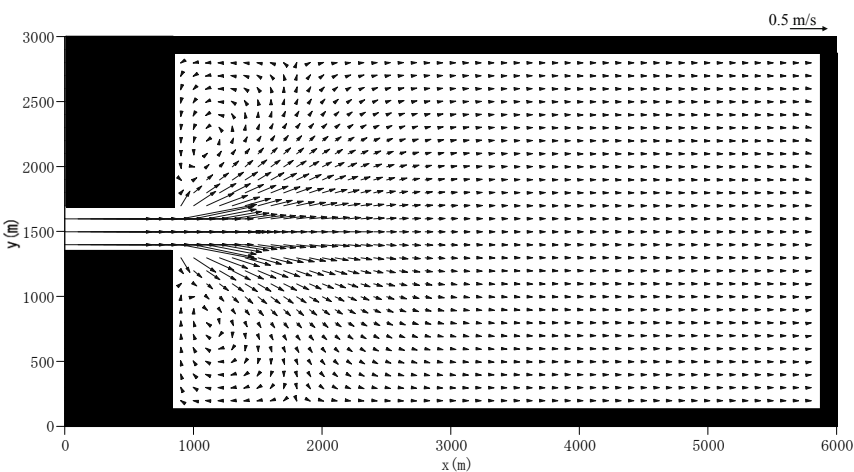

(a) CASE 2

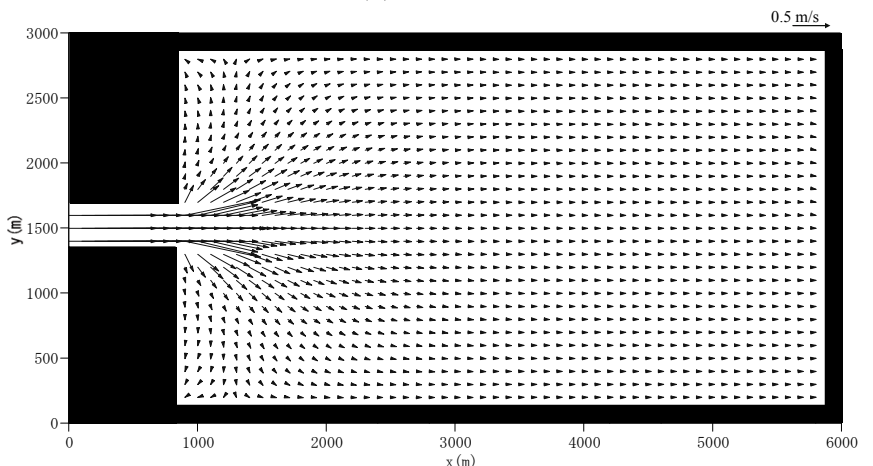

(b) CASE 3

Fig. 7 Depth-averaged currents distribution at the strongest flood tide.

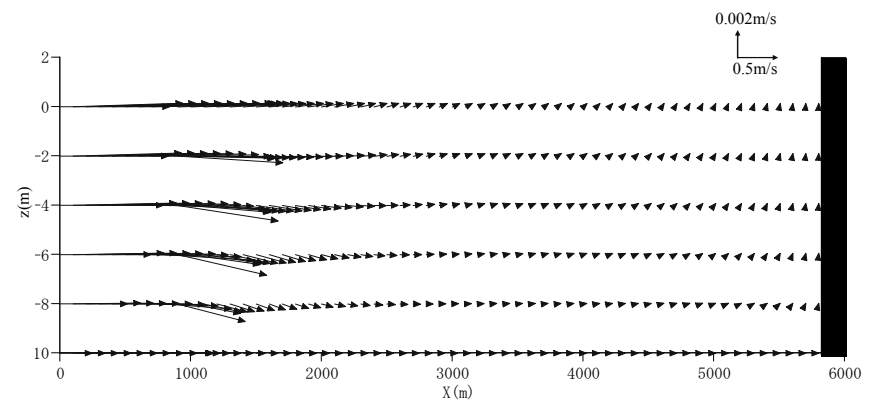

(a) CASE 2

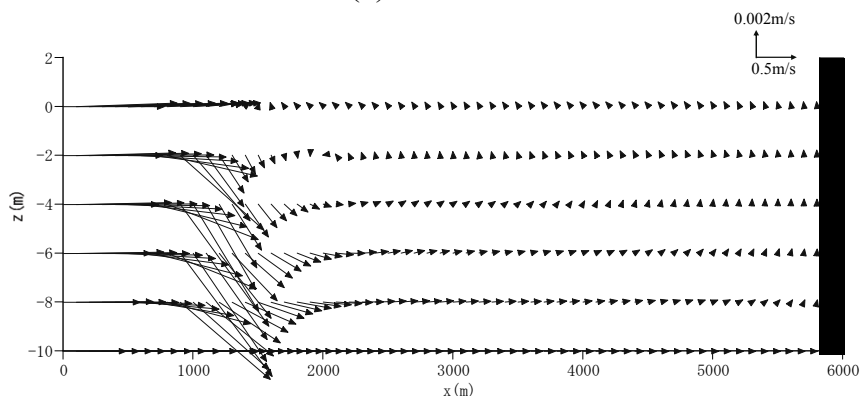

(b) CASE 3

Fig. 8 Vertical currents distribution at the strongest flood tide.

The depth-average current vectors and the vertical section at $y=1500 m$ for CASE 1 are shown in Fig. 6. As for CASE 1 with salinity change only, the outflow direction was seen at the surface and the inflow direction was seen at the bottom. The depth-average current vectors for the strongest flood tide (36 hours later), and the vertical section of currents distributions at $y=1500 \mathrm{~m}$ for CASE 2 and CASE 3 are shown in Figs. 7 and 8 . In these figures, the current distribution was effected due to the salinity change and show higher current values in CASE 3 than in CASE 2.

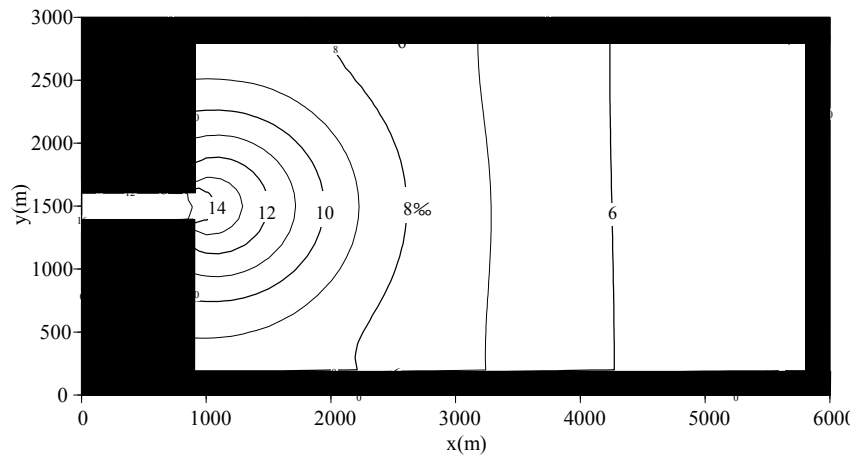

(a) Horizontal salinity distribution at the bottom layer.

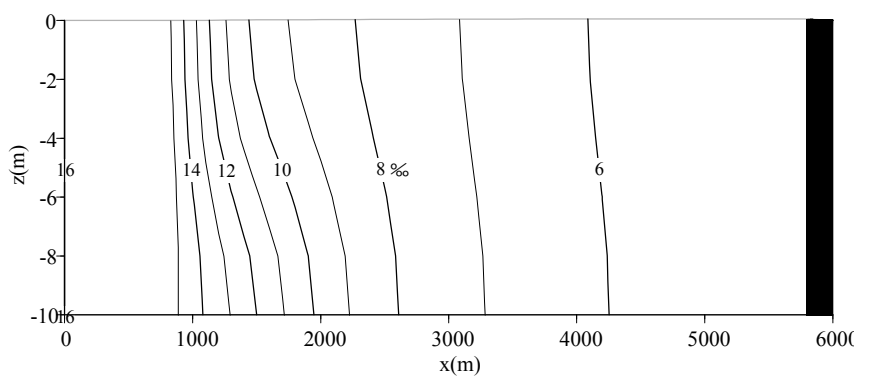

(b) Vertical salinity distribution $(y=1500 m)$.

Fig. 9 Salinity distributions for the strongest flood tide of CASE 3.

The horizontal and vertical salinity distribution of CASE 3 for the strongest flood tide was computed and shown in Fig. 9. The circumstances of the salinity spreading in the horizontal direction at the flood tide were obtained, and the salinity passed through the basin entrance to the basin head with a concentric circular spreading. In case of high amplitude, the salinity was diffused quickly reaching the basin head. The salinity intrusion at the bottom layer is higher than at the surface as confirmed in the vertical section as shown in Fig. 9(b). The model test was able to predict the performance of salt intrusion.

\section{APPLICATION TO THE ARIAKE SEA}

The Ariake Sea is the long inner bay on the Kyushu Island, on the west part of Japan. The amplitude of tidal wave increases gradually from the mouth to the head of bay areas. At the flood tide, the tidal range is about $3.0 \mathrm{~m}$ in the bay mouth area, and it becomes bigger in the bay head area with the tidal range of 4.5 5.0m (Kato and Seguchi, 2001). Therefore, the mean tidal range in the sea is about $3 \mathrm{~m}$. The model was applied to the prediction of the tidal currents and thermodynamics in the north bay of Ariake Sea in order to be verified and calibrated. The water depth contour map of the study area is shown Fig. 10. 


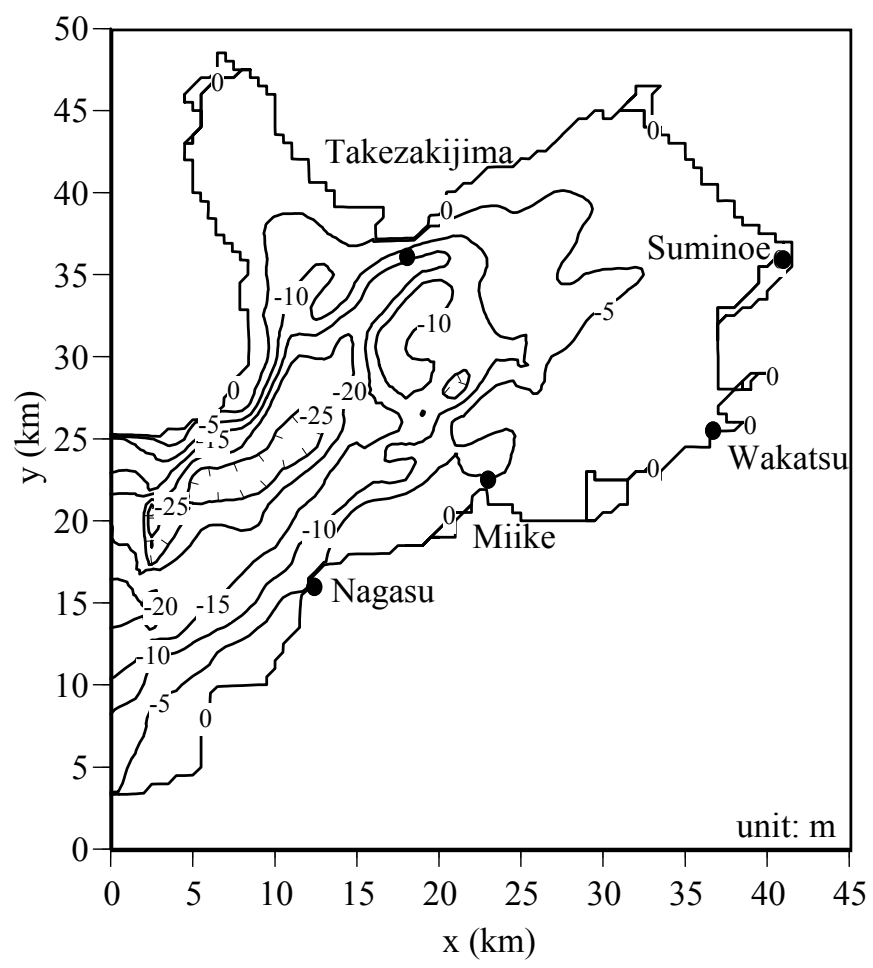

Fig. 10 Depth contour map of the north bay of Ariake Sea.

The horizontal computational domain considered in this study covered an area of $50 \mathrm{~km}$ (NS) by $45 \mathrm{~km}$ (EW), with a grid interval of $500 \mathrm{~m}$. The horizontal and vertical eddy viscosity coefficients were 10.0 and 0.1 , respectively; the Chezy coefficient was 10.0; the horizontal and vertical diffusion coefficients were 1000.0 and 0.001 , respectively; the amplitude at the open boundary was set at $1.32 \mathrm{~m}$; the period was $12 h$; the total model run was $48 h$; and the time step was $1.0 \mathrm{~s}$. The water depth was divided into five equal layer thicknesses. The slip condition of sea bed was assumed. The effect of salinity and water temperature changes were considered. The wind stresses on sea surface and the inflow of Chikugo River were neglected. The water level fluctuation type was $\eta=-a \sin [k y \sin (\alpha-\sigma t)], \alpha=0$, in which $\alpha$ is the incidence angle of the tidal wave in the open seaside boundary and $k$ is the wave number, which was computed using the long wave theory.

The boundary conditions of water level forcing, salinity, and water temperature were defined at the open sea boundary. The predominant tidal constituent is $M_{2}$ in the bay (Isozaki and Kitahara, 1977). A constant salinity rate of $34 \%$ and a constant water temperature of $29^{\circ} \mathrm{C}$ were set at the open boundary. The computation was started cold with an initial salinity concentration of $30 \%$ and initial temperature of $25^{\circ} \mathrm{C}$.

Since we assume that there is neither current nor elevation in the sea initially, the calculated tide is a type of progressive wave in the early stage. Therefore, the computation of at least four tidal cycles were required to get periodically stationary solution, and only the computed results for the fourth tidal cycle were taken and analyzed.

The computed amplitudes were increased gradually in the direction of the bay head, and the comparisons between the observed and computed amplitudes and phases at various tidal stations are shown in Table 4 and 5 . The computed amplitudes agreed well with the observations provided by Isozaki and Kitahara (1977), except at Miike station with a root-mean square error (RMSE) of $2.5 \%$. The phase angles also agreed well with the observations, except at Suminoe station with RMSE of $4.9 \%$. Both the computed amplitudes and phase angle results were improved when the density currents were considered in the computations as compared with the computed results from a previous study that excluded the density change. In addition, the circumstances of WAD in the tidal marsh were demonstrated clearly, as shown in Fig. 11.

Table 4 Observed and computed amplitudes during $M_{2}$.

\begin{tabular}{|c|c|c|c|c|c|c|c|}
\hline \multirow{2}{*}{$\begin{array}{c}\text { Station } \\
\text { name }\end{array}$} & Observed & \multicolumn{3}{|c|}{$\begin{array}{c}\text { Computed } \\
\text { (no salinity) }\end{array}$} & \multicolumn{3}{c|}{$\begin{array}{c}\text { Computed } \\
\text { (salinity) }\end{array}$} \\
\cline { 2 - 8 } & $(m)$ & $(m)$ & RMSE & $\begin{array}{c}\text { RMSE } \\
\%\end{array}$ & $(m)$ & RMSE & $\begin{array}{c}\text { RMSE } \\
\%\end{array}$ \\
\hline Nagasu & 1.47 & 1.47 & 0.00 & 0.0 & 1.47 & 0.00 & 0.0 \\
\hline $\begin{array}{c}\text { Takesakij } \\
\text { ima }\end{array}$ & 1.58 & 1.58 & 0.00 & 0.0 & 1.57 & 0.01 & 0.6 \\
\hline Miike & 1.59 & 1.57 & 0.02 & 1.3 & 1.55 & 0.04 & 2.5 \\
\hline Wakatsu & 1.61 & 1.73 & 0.12 & 7.5 & 1.62 & 0.01 & 0.6 \\
\hline Suminoe & 1.72 & 1.72 & 0.00 & 0.0 & 1.72 & 0.00 & 0.0 \\
\hline
\end{tabular}

Table 5 Observed and computed phase angles during $M_{2}$.

\begin{tabular}{|c|c|c|c|c|c|c|c|}
\hline \multirow{2}{*}{$\begin{array}{c}\text { Station } \\
\text { name }\end{array}$} & Observed & \multicolumn{3}{|c|}{$\begin{array}{c}\text { Computed } \\
\text { (no salinity) }\end{array}$} & \multicolumn{3}{|c|}{$\begin{array}{c}\text { Computed } \\
\text { (salinity) }\end{array}$} \\
\cline { 2 - 9 } & $(d e g)$ & $(d e g)$ & RMSE & $\begin{array}{c}\text { RMSE } \\
\%\end{array}$ & $($ deg $)$ & RMSE & $\begin{array}{c}\text { RMSE } \\
\%\end{array}$ \\
\hline Nagasu & & 258 & & & 258 & & \\
\hline $\begin{array}{c}\text { Takesaki } \\
\text { jima }\end{array}$ & 259 & 273 & 14 & 5.4 & 259 & 00.0 & 0.0 \\
\hline Miike & 259 & 273 & 14 & 5.4 & 259 & 00.0 & 0.0 \\
\hline Wakatsu & 262 & 287 & 25 & 9.5 & 262 & 00.0 & 0.0 \\
\hline Suminoe & 267 & 289 & 22 & 8.2 & 280 & 13.0 & 4.9 \\
\hline
\end{tabular}

A representative example of the depth-average tidal currents during the ebb and flood tides at various times is shown in Fig. 11 from this figure, the tidal currents for the northern bay of Ariake Sea form a round-trip style during the flood and ebb tides. The fastest computed currents of more than $1.0 \mathrm{~m} / \mathrm{s}$ were seen near Nagasu station. The observed tidal currents near Nagasu during the flood tide provided by Isozaki and Kitahara (1977) had a fastest flow of more than $1.0 \mathrm{~m} / \mathrm{s}$. The strong current zone, defined as having speed of more than $1.0 \mathrm{~m} / \mathrm{s}$, covers the region near Nagasu station. The currents from Miike station to the northern part are relatively weak, but speed of more than $0.5 \mathrm{~m} / \mathrm{s}$ is still seen near the head. 
In the previous study that excluded the thermodynamics circulation (Abualtayef et al., 2008), the tidal currents were generally somewhat slower than the observed currents over the Wakatsu tidal flat area, where the observed currents
(Sasaki et al., 2005) have speeds about twice those of the computed currents. However, by considering the density changes in the computations, the model prediction of tidal currents was improved especially at the bay head.

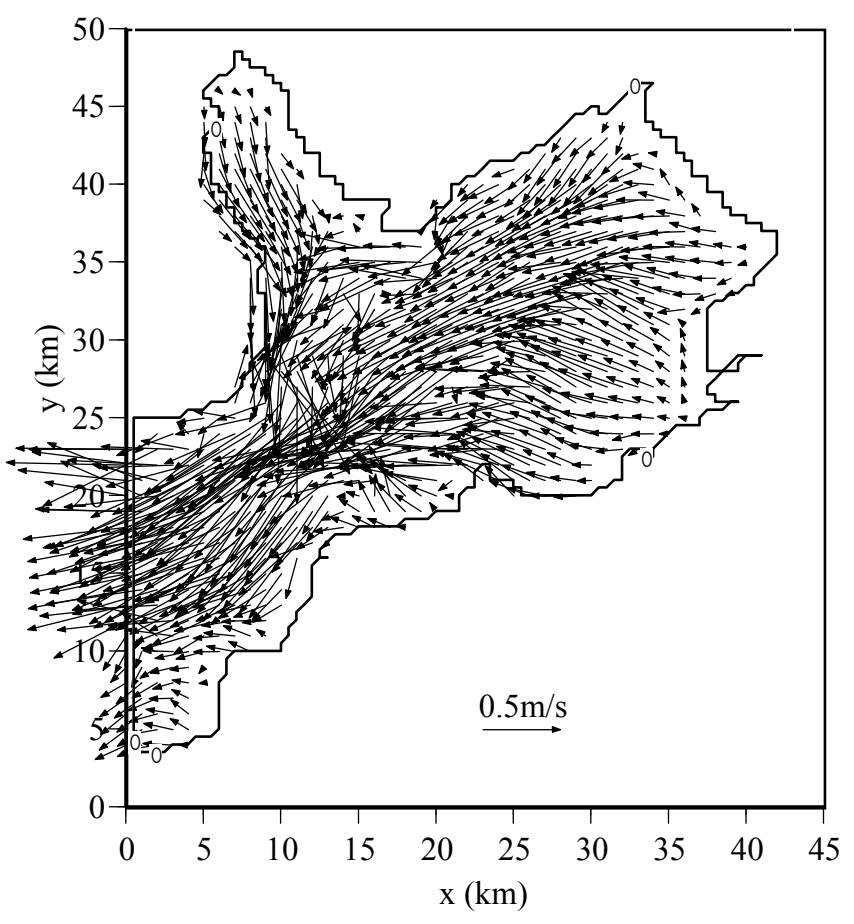

(a) $t=36.5 \mathrm{~h}$

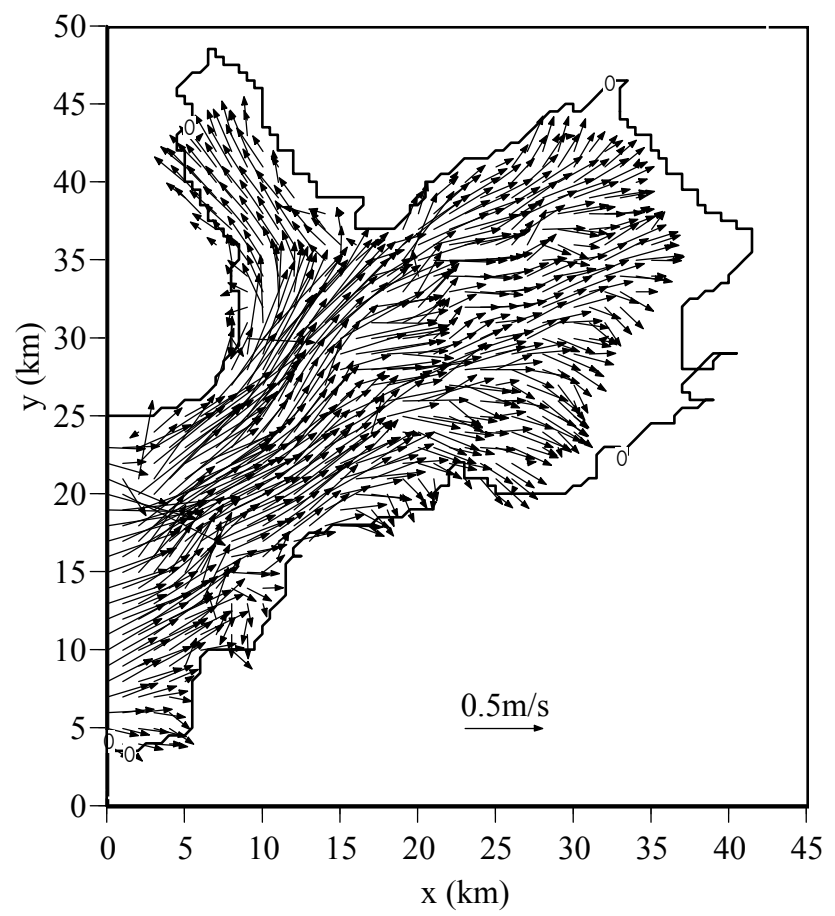

(c) $t=42 h$

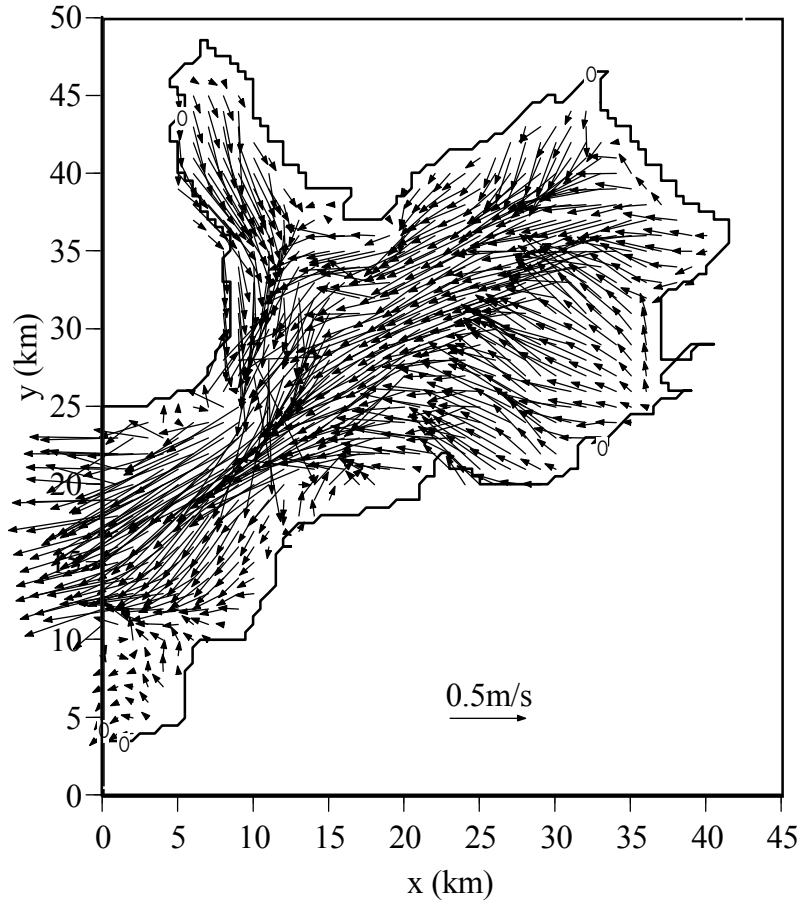

(b) $t=38 \mathrm{~h}$

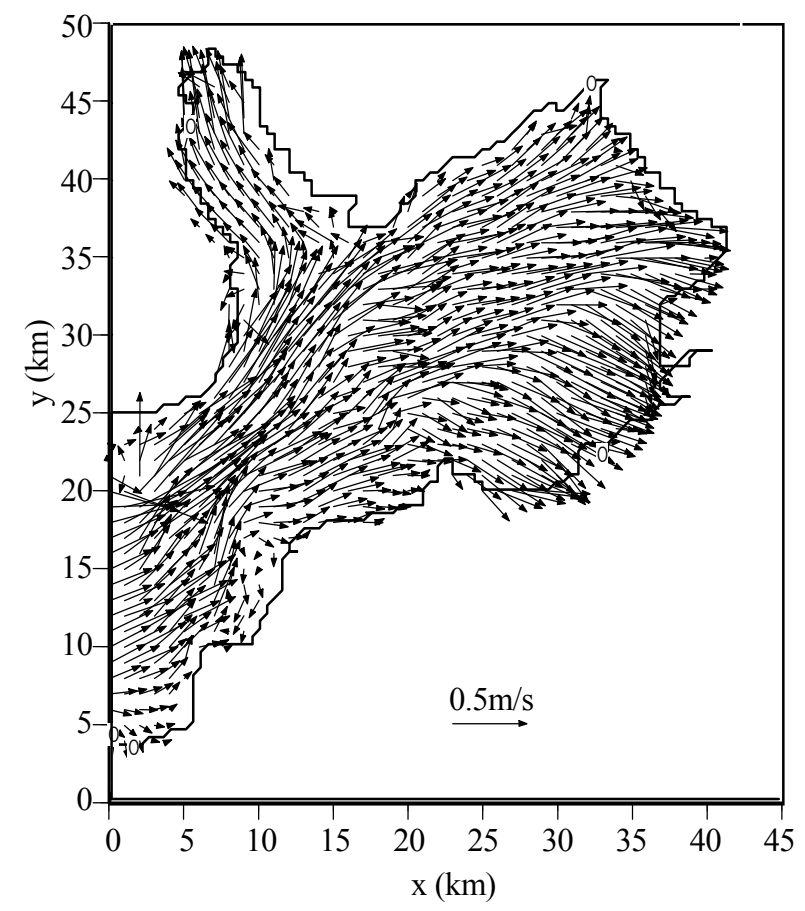

(d) $t=45 h$

Fig. 11 Depth-average tidal currents during the ebb tide(a, b); and (c, d) the flood tide. 


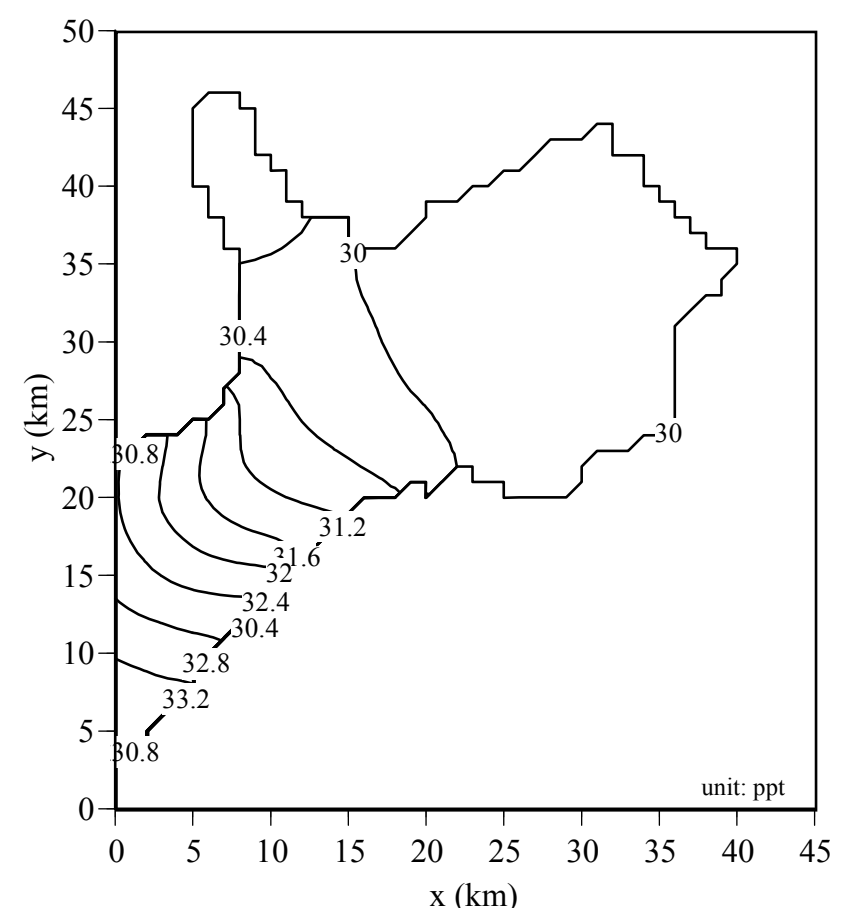

(a) Salinity distribution during the ebb tide $(t=38 h)$.

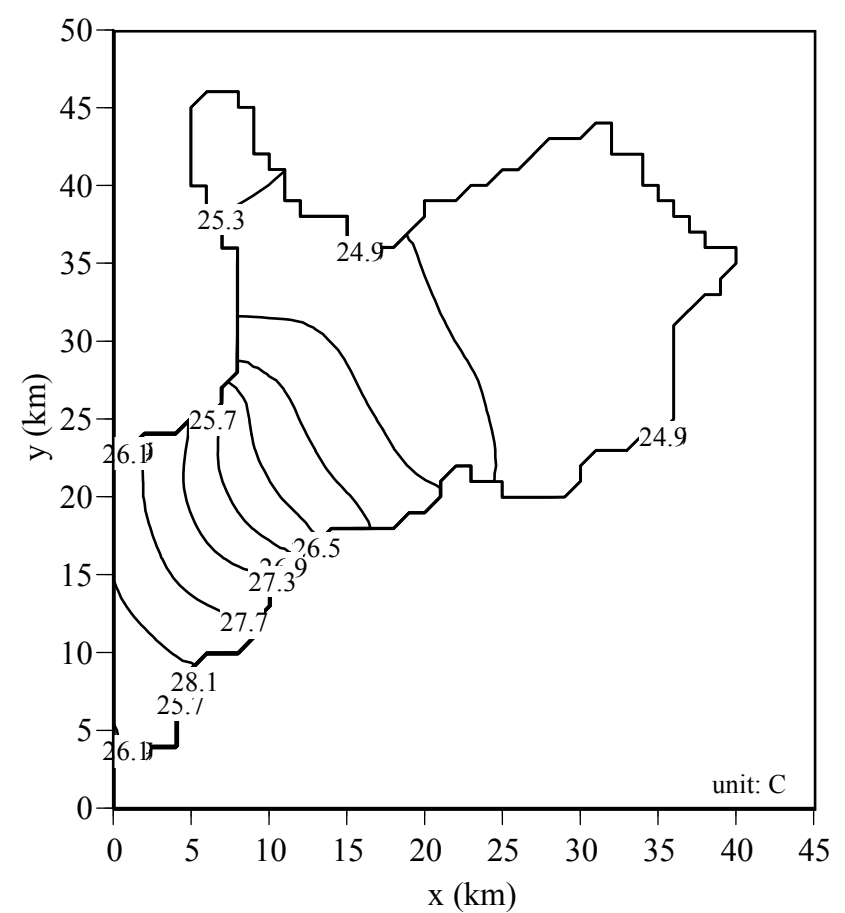

(c) Temperature distribution during the ebb tide $(t=38 h)$.

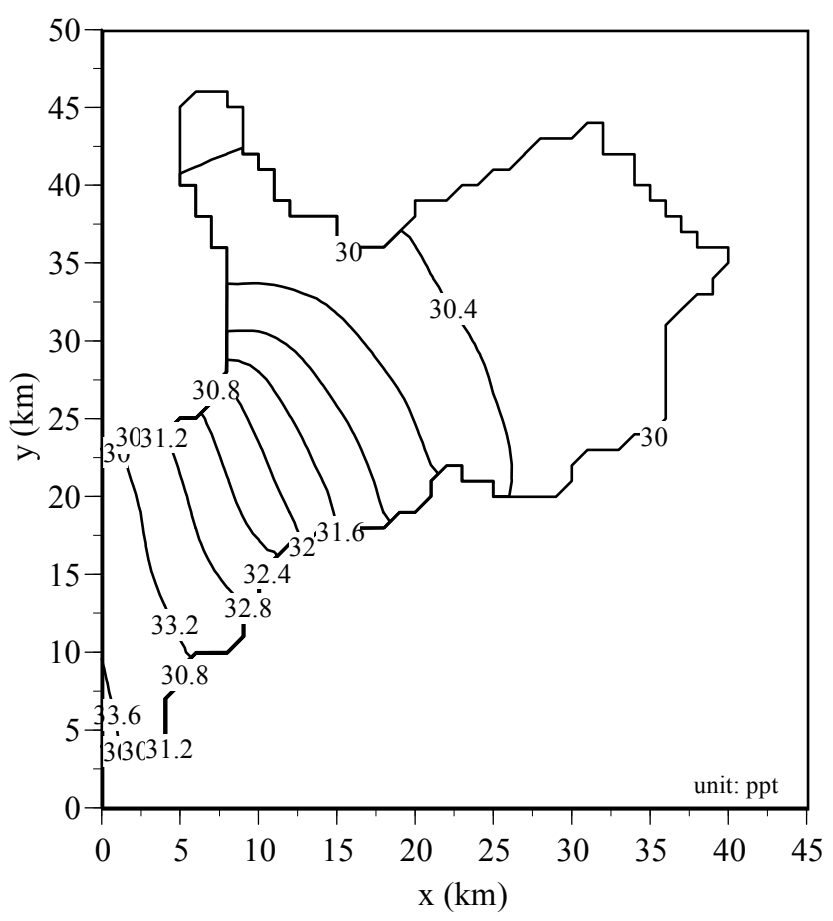

(b) Salinity distribution during the flood tide $(t=45 h)$.

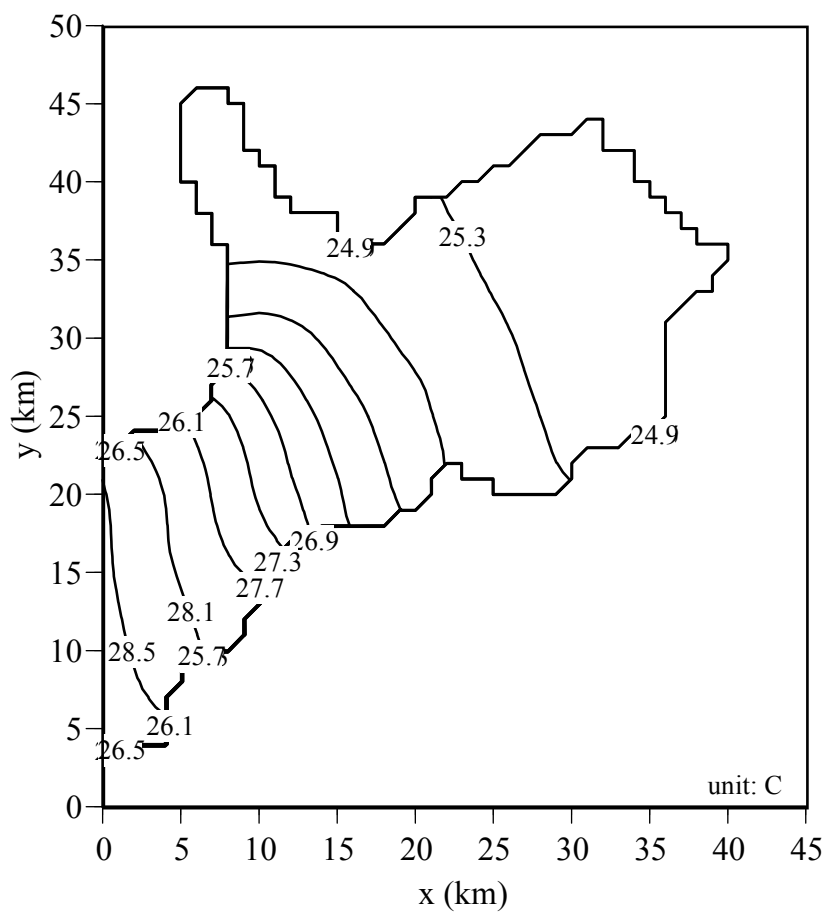

(d) Temperature distribution during the flood tide $(t=45 h)$.

Fig. 12 Salinity distribution and temperature distribution during the ebb tide $(t=38 h)$ and the flood tide $(t=45 h)$.

Figs. 12(a) and (b) show the computed surface salinity distribution during the ebb and flood tides at various indicated times. After analyzing these figures, the salinity concentration was diffused gradually through the sea from the bay entrance to the bay head. The salinity was spread periodically with time. It was found that the model needs to run more than 24 days to reach the salinity rate of $34 \%$ for the whole model domain. The salinity concentrations at the bottom layers are slightly higher than those at surface layers during the ebb tides. The salinity in the shallow regions has 
the same magnitude over the vertical direction, which was due to the well mixing process at these areas. The results of temperature distribution were behaved more or less same as the salinity distribution. In general, the temperature values along the depth were the same due to the well mixing process over shallow waters.

\section{CONCLUSIONS}

In this article, the hydrodynamic and thermodynamic circulations in coastal area were described, and this model was able to consider the vertical distribution of the flow in the tidal flat region. The applicability of the model was demonstrated on the rectangular basin with the density current. The appearance of symmetrical diffusion along the centerline of basin was confirmed and the salt wedge with the density current circulation was produced.

In the model application to the Ariake Sea, the hydrodynamic and thermodynamics circulation were predicted. The numerically predicted results were well consistent with the field observations and they were improved with considering the thermodynamics in the computations as compared with the previous study results. The tidal currents for the northern bay of Ariake Sea form a round-trip style during the flood and ebb tides. The salinity concentration was gradually diffused through the sea from the open boundary to the bay head. In general, the salinity was spreading periodically with time, and well mixing process of the salinity and temperature over very shallow water was recognized.

As a future work, further developments are needed to improve the model prediction; these include the river flows, time-series observations for water level, tidal currents, salinity, and temperature.

\section{ACKNOWLEDGEMENTS}

This study was supported by the Japanese Society for the Promotion of Science, JSPS.

\section{REFERENCES}

Abualtayef, M. Kuroiwa, M. Tanaka, K. Matsubara, Y. and Nakahira, J., 2008. A three dimensional hydrostatic modeling of a bay coastal area. Journal of Marine and Science and Technology, 13, pp. 40-49.

Abualtayef, M. Kuroiwa, M. Tanaka, K. Matsubara, Y. and Nakahira, J., 2007. A numerical simulation of windinduced flows in Ariake Sea. Journal of Applied Sciences, 7, pp. 1446-1451.

Heaps, N.S., 1972. Estimation of density currents in the Liverpool Bay area of the Irish Sea. Geophysical Journal, the Royal Astronomical Society, 30, pp. 415-432.

Isozaki, I. and Kitahara, E., 1977. Tides in the bays of Ariake and Yatsushiro. The Oceanographical Magazine, 28, pp. $1-32$.

Jin, X. and Kranenburg, C., 1993. Quasi-3D numerical modeling of shallow-water circulation. Journal of Hydraulic Engineering, ASCE, 119, pp. 458-472.

Kato, K. Tanaka, N. and Nadaoka, K., 1979. Tidal simulation on tidal marsh and numerical forecasting of its topographic deformation. Port and Harbor Technical Research Institute 18, pp.3-75.

Kato, O. and Seguchi, M., 2001. The flow features and the forming process of tidal flat in Ariake Sea. Proceedings of the International Conference on the Environmental Management of Enclosed Coastal Seas, 5, pp. 6-386.

Koutitas, C. and O'Connor, B., 1980. Modeling 3D windinduced flows. Journal of Hydraulic Division, ASCE, 11, pp. 1843-1865.

Oey, L.Y., 2005. A wetting and drying scheme for POM. Ocean Modeling , 9, pp. 133-150.

Sasaki, K. Matsukawa, Y. and Tsutsumi, H., 2005. The ecosystem regeneration of the Ariake Sea (in Japanese). The Oceanographic Society of Japan, Koseisha Koseikaku, Tokyo.

Yu, Z. and Kyozuka, Y., 2004. A simplified moving boundary treatment in MEC model. International Journal of Offshore and Polar Engineering, ISOPE , 14, 241-246.

Zhang, Q.Y. and Gin, KYH., 2000. 3D numerical simulation for tidal motion in Singapore's coastal waters. Coastal Engineering, 39, pp. 71-92. 